\title{
Experimental Study on the Sound Absorption Properties of Finger Millet Straw, Darbha, and Ripe Bulrush Fibers
}

\author{
K. M. Rakesh, ${ }^{1}$ Ramachandracharya Srinidhi, ${ }^{1}$ S. Gokulkumar ${ }^{(D},{ }^{2}$ K. S. Nithin, ${ }^{3}$ \\ S. Madhavarao, ${ }^{4}$ S. Sathish, ${ }^{2}$ Alagar Karthick (D), ${ }^{5}$ M. Muhibbullah (D), \\ and Sameh M. Osman ${ }^{7}$ \\ ${ }^{1}$ Department of Mechanical Engineering, JSS Science \& Technology University, Mysuru 570006, India \\ ${ }^{2}$ Department of Mechanical Engineering, KPR Institute of Engineering and Technology, Coimbatore 641407, Tamilnadu, India \\ ${ }^{3}$ Department of Chemistry, The National Institute of Engineering, Mysuru 570008, India \\ ${ }^{4}$ Department of Mechanical Engineering, Sagi Rama Krishnam Raju Engineering College, Bhimavaram 534204, \\ Andhra Pradesh, India \\ ${ }^{5}$ Renewable Energy Lab, Department of Electrical and Electronics Engineering, KPR Institute of Engineering and Technology, \\ Coimbatore 641407, Tamil Nadu, India \\ ${ }^{6}$ Department of Electrical and Electronic Engineering, Bangladesh University, Dhaka 1207, Bangladesh \\ ${ }^{7}$ Chemistry Department, College of Science, King Saud University, P.O. Box 2455, Riyadh 11451, Saudi Arabia
}

Correspondence should be addressed to M. Muhibbullah; m.muhibbullah@bu.edu.bd

Received 23 October 2021; Revised 29 November 2021; Accepted 2 December 2021; Published 28 December 2021

Academic Editor: ubo Kri k

Copyright (C) 2021 K. M. Rakesh et al. This is an open access article distributed under the Creative Commons Attribution License, which permits unrestricted use, distribution, and reproduction in any medium, provided the original work is properly cited.

\begin{abstract}
Nowadays, emerging noise pollution by external factors causes harmful diseases in human beings. The development of a bio-based filler or panel will help to eliminate some unwanted noise in working places and living rooms. This work aimed to develop an ecowaste fiber (leftover after harvesting)-based sound absorber and analyze its capabilities for sound absorption. The ecowaste fibers are collected by the gleaning process, i.e., the process of collecting leftovers from fields. The sound absorption capabilities of three natural fibers extracted from Eleusine coracana (Finger millet) straw, Desmostachya bipinnata (Darbha), and Typha domingensis (Ripe bulrush) plants are investigated in this study, both individually and in hybrid combinations. The sound absorption property mainly depends on factors such as porosity, flow resistivity, thickness, density, and tortuosity. Fiber length and fiber type play a significant role when fibers are arranged individually or in hybrid combinations. The stacking effect on the sound absorption coefficient of hybridized fiber arrangement was experimentally analyzed. The sound absorption coefficient $(\alpha)$ was found to be lower in the range of $1000 \mathrm{~Hz}-2500 \mathrm{~Hz}$ for all the combinations. As a homogenous fiber arrangement, the darbha fiber exhibited the better NRC (noise reduction coefficient) of 0.86 for $50 \mathrm{~mm}$ thickness among three different fibers and as a hybrid composition, ripe bulrush and darbha fibers exhibited NRC of 0.90 which is more capable of absorbing sound in the critical frequency range of 500 to $2000 \mathrm{~Hz}$. These types of natural fiber fillers are highly capable of better sound absorbing and used in the applications such as classrooms, sound recording rooms, and theatres.
\end{abstract}

\section{Introduction}

In the modern era, one such issue is noise, and it is considered undesirable. Continuous exposure to noise levels of $80 \mathrm{~dB}$ or higher for more than eight hours a day increases tension and alters breathing patterns [1]. Since the inventions of new machinery and automobiles, noise control has become a significant concern. The initial solution to address these noise problems is to develop sound absorbers, barriers, and diffusers. Recently, researchers are working to develop more cost-effective and environmentally sustainable acoustic materials to address the concerns mentioned earlier.

Initially, manufacturers of sound absorbers used asbestos for cost-effectiveness. Later, it was proven that it has a carcinogenic dangerous emission on both humans and animals. Since then, the majority of industries have limited 
the use of asbestos and utilized synthetic fibers as a partial replacement. Besides asbestos, other materials were used in the past for sound absorption properties. However, it is also found to be hazardous when inhaled and results in lung diseases [2]. Numerous researchers have recently investigated the acoustic absorption properties of different natural biofibers, including kenaf fiber [3], coconut coir [4], oil palm fruits [5], and pineapple leaf fiber [6-8]. These studies demonstrated a significant potential for natural fibers to be used as insulating materials. Additionally, some researchers used kenaf/polypropylene nonwoven composite [9], coir composite [10], and oil palm fiber based composite [11] to establish its acoustic capabilities. Natural fibers performed exceptionally well when combined with other fibers and matrices in various composites. Camellia sinensis/Ananas comosus/glass fiber based composites exhibited good sound absorption properties for $25 \%$ by weight of Camellia sinensis because of its porous nature [12]. The chicken feather fibers are added by different weight percentages to the wood particleboard, and the result showed that the 5\% chicken feather content was found to be a reasonable combination for maintaining acceptable fire characteristics in panels [13]. Coir-banana-polypropylene hybridization was found to have a lower sound transmission loss than individual fiber composites [14] and short ramie fiber composites had a higher SAC value than ramie fabric-based composites $[15,16]$. The use of natural fibers as filler materials in sound absorption applications yields good results. The porous absorbers, panel absorbers, and membranes are the types of sound absorbers that permit the passage of sound and airwaves through materials with channels and cavities. According to the literature, sound absorbers or proofers are fibrous, cellular, or granular [17]. The fibers are pretreated with some chemical agents to remove their foreign substances for enhancing better adhesion. The results indicate that fibers that have been physically and chemically treated with some chemical agents have a higher NRC (noise reduction coefficient) than those that have not been treated. The surface modification and volume fraction of fiber increase interfacial adhesion, which improves both mechanical and acoustic absorption properties [12].

The sound absorption coefficient (SAC) results support the use of insulation panels made of tree bark as structural elements for noise reduction in residential structures, while also offering new thrust areas for further research in this subject [18]. Tudor et al. (2021) [19] have demonstrated that bark-based boards with fine-grained particles perform better in terms of sound absorption coefficient values than boards with coarse-grained particles. It is required to consider bark boards greater than $50 \mathrm{~mm}$ in thickness for their capability of performing an acoustic function in border structures. At less than $50 \mathrm{~mm}$ in thickness, the individual layers of the bark pieces are not overlapped, resulting in huge air spaces and an ineffective sound absorber.

Olcay and Kocak (2020) [20] investigated the effects of alkali treatment $(\mathrm{NaOH})$ and fiber reinforcement ratios on the mechanical and sound absorption of PU foam-based composites. These fibers were pretreated with $10 \%$ alkali for 15 minutes. The composition with $5 \%$ by weight of the fiber exhibits a higher
SAC of 0.41. These composites can be applied in the construction field and automotive parts where noise reduction is more desirable. The results reveal that agricultural waste products can be used as an additional alternative to increase the SAC of material without an increase in thicknesses [21]. To enhance the composite's acoustic properties, natural fiber coir was added with different blend ratios of reclaimed viscose (in percent), namely, $70: 30 ; 60: 40 ; 50: 50$; and $60: 40$, using a needle-punching technique [22]. The results reveal that when the viscosity content of the product increases, acoustic absorption also increases linearly. Also, the increased viscosity results in increased moisture absorption and the addition of fiber weight. Because of the presence of unidirectional coir fiber, the air resistivity increased with the denser fiber. The purpose of the layer's thickness is to increase the longer path for incident sound waves to pass through the material to lose more energy.

Flax has superior mechanical qualities when compared to other natural fibers [22] and is the strongest natural fiber in terms of properties, namely, tensile strength and crack inhibitor [23]. Additionally, flax fiber mixed with the epoxy demonstrated much greater vibration and sound dampening at low densities. In general, low permeability is considered a positive factor in enhancing the acoustic absorbance capacity in the lowfrequency region [24]. Numerous researchers have already created natural fiber based composites using polymeric granules and fibers as an additional reinforcement that increases sound and physical properties [25]. Mamtaz et al. [26] have manufactured and analyzed novel composites comprised of natural fibers such as unidirectional coconut coir fibers and flakes form of rice husks. The results indicated that the produced composites exhibit an excellent sound absorption performance (SAC of 0.73 ) below $1500 \mathrm{~Hz}$. This was attributable to the fact that adding rice husk filler to composites leads to the filling of the pores, lowering the porosity and increasing the surface contact area. These factors contribute to an increase in flow resistivity, which improves the SAC in low-frequency bands.

Berardi and Iannace [27] measured the SAC of kenaf samples by varying thicknesses and densities at 50 to $2500 \mathrm{~Hz}$. When the density of fibrous increases from 45 to $110 \mathrm{~kg} / \mathrm{m}^{3}$, the SAC reaches 0.92 at a frequency of $2300 \mathrm{~Hz}$. Lim et al. [28] investigated the SAC of kenaf fiber based fillers at $530 \mathrm{~Hz}$ to $4600 \mathrm{~Hz}$ with a sample thickness of $25 \mathrm{~mm}$ to $30 \mathrm{~mm}$ and a density of $160 \mathrm{~kg} / \mathrm{m}^{3}$. The result reveals that SAC is greater than 0.5 above $600 \mathrm{~Hz}$, while the SAC exceeds 0.87 above $1750 \mathrm{~Hz}$. Similarly, the investigation on the sound absorption of the kenaf fiber based composite sample also showed a better SAC of 0.89 by varying thicknesses and densities [29]. The SAC was measured using both impedance tube and reverberant chamber methods. The results indicate that samples having a thickness of $35 \mathrm{~mm}$ with a bulk density of $150 \mathrm{~kg} / \mathrm{m}^{3}$ exhibited better SAC and NRC of 0.65 and 0.53 , respectively. Hao et al. [30] investigated the sound absorption characteristics of $50 \%$ kenaf and $50 \%$ polypropylene blended composite having $6 \mathrm{~mm}$ of thickness. It has been reported that SAC increases as the frequency of sound intensity increases.

The sustainable reuse of waste biomaterials in recent years has become crucial for environmental and economic preservation. Rice husk, ripe bulrush, and darbha are ecowaste materials (leftover fibers) found to be abundant in 
many regions. The present study aims to investigate the sound absorption properties (SAC- $\alpha$ and NRC) of finger millet straw, darbha, and ripe bulrush fibers for different thicknesses. Additionally, their hybrid combinations are investigated to understand the effect of hybridization and increase of thickness on the sound absorbing properties.

\section{Materials and Methods}

2.1. Materials. Straws of finger millet (Eleusine coracana) were collected from a harvesting site in the district of Mysuru, India. Finger millet straw fibers were obtained upon the chemical treatment of finger millet straws and the extraction process as shown in Figure 1. Darbha fibers were extracted from darbha plants (Desmostachya bipinnata) grown along the Cauvery riverbanks and the ripe bulrush fibers from Typha domingensis, a weed plant that grows along the banks of lakes in the Mysuru district. Chetana Chemicals, Mysuru, supplied chemicals, namely, sodium hydroxide, hydrogen peroxide, acetone, and double-distilled water to carry out the chemical pretreatments.

\subsection{Fiber Extraction and Chemical Treatment. Finger millet} straws were collected at the harvesting site during the extraction process of finger millet grains from the harvested finger millet plant. As illustrated in Figure 1, the collected finger millet straws were chopped to remove the interconnecting straw buds. The resulting bud fewer straws were washed five times with doubledistilled water. This facilitated the removal of dust and dirt particles that adhered to the straw surface. The water-washed straws were then sun-dried for 12 hours appropriately. Darbha fibers were extracted from the plant by hand separation, after washing with double-distilled water and sun drying as shown in Figure 2. Lastly, ripe bulrush fibers were extracted from ripe bulrush grass using the combined retting process [31] and prewashed with distilled water before being dried in the sunlight as shown in Figure 3. Following sun-drying, the fibers and straws were alkali-treated ( $10 \% \mathrm{NaOH}$ treatment for 24 hours) to remove any remaining dust and impurities [32]. They were washed with double-distilled water to remove any alkali substances that remained on the fiber surface. The obtained fibers and straws were sun-dried until moisture content was decreased to less than $2 \%$. Additionally, the fibers of darbha and ripe bulrush were used to prepare samples. However, the finger millet straws were further treated with hydrogen peroxide and acetone $(5 \mathrm{ml}$ of hydrogen peroxide and $95 \mathrm{ml}$ of acetone in a $100 \mathrm{ml}$ solution) to obtain fine straw fibers of finger millet for sample preparation.

2.3. Fiber Properties. The fiber properties, such as fiber length, diameter, and density of all three fibers, are determined for the three different natural fibers used are listed in Table 1.

2.4. Preparation of the Testing Specimens. Chemically treated fibers of $300 \mathrm{~mm}$ in length were filled into plastic mesh for subsequent insertion into an impedance test tube as shown in Figure 4. The plastic mesh helps to hold the fibers tightly and has a negligible effect on the sound absorption of fibers.
Samples are coded as S1-S3 (individual fibers), S4-S9 (stacked hybrid combinations), and S10-S12 (stacked hybrid combinations). The thickness of the samples containing individual fibers (S1, S2, and S3) are kept constant as $50 \mathrm{~mm}$ and hybrid combinations ( 44 to $\mathrm{S} 12$ ) are kept totally as $50 \mathrm{~mm}$ and $25 \mathrm{~mm}$ individually. As shown in Table 2, S4-S9 are stacked hybrid combinations of fibers, whereas S10, S11, and S12 are homogenous hybrid combinations. All these samples (from S4 to S12) contain two distinct fibers, each contributing $25 \mathrm{~mm}$ in thickness, resulting in the formation of a $50 \mathrm{~mm}$ thick hybrid fiber combination. Thus, all samples from S1 to S12 were examined for their sound absorption properties-individual fibers (S1, S2, and S3), stacked hybrid fibers (S4-S9), and homogenous hybrid fibers (S10, S11, and S12), as illustrated in Figure 5.

2.5. Experimental Setup. The sound absorption coefficients $(\alpha)$ of individual and hybrid fibers were determined using an impedance tube according to ISO 10534 (2) 1998 standard [33]. Figure 4 depicts the experimental setup with an impedance tube, which includes an impedance tube, a data analyzer, and a data acquisition system. The sample holder has a diameter of $45 \mathrm{~mm}$, the microphones are $30 \mathrm{~mm}$ apart, and the distance between the test sample and the nearest microphone is $90 \mathrm{~mm}$. The sound absorption properties were determined over a frequency range of $100 \mathrm{~Hz}$ to $4500 \mathrm{~Hz}$ and at sample thicknesses of $10 \mathrm{~mm}$, $20 \mathrm{~mm}$, and $50 \mathrm{~mm}$. To investigate the effect of air gap on the sound absorption coefficient of fiber, a $10 \mathrm{~mm}$ air gap is provided between the fibers and the sample holder. Because the fibers are held in a net, a $10 \mathrm{~mm}$ air gap can be maintained behind fiber samples. To begin, fibers (wrapped in a net) measuring $50 \mathrm{~mm}$ in thickness are inserted into the sample holder in such a way that they are entirely in contact with the sample holder's innermost surface. Using the scale engraved on the sample holder, precisely move the contact surface of the sample holder back to ensure a $10 \mathrm{~mm}$ air gap. The average sound absorption coefficient $\left(\mathrm{SAC}_{\mathrm{avg}}\right)$ and noise reduction coefficient (NRC) were calculated from (1) and (2), respectively,

$$
\begin{aligned}
\mathrm{SAC}_{\mathrm{avg}} & =\frac{\alpha_{125}+\alpha_{250}+\alpha_{500}+\alpha_{1000}+\alpha_{2000}+\alpha_{4000}}{6}, \\
\mathrm{NRC} & =\frac{\alpha_{250}+\alpha_{500}+\alpha_{1000}+\alpha_{2000}}{4},
\end{aligned}
$$

where SAC is sound absorption coefficient, NRC is noise reduction coefficient, and $\alpha_{n}$ is sound absorption coefficient of " $n$ th" frequency.

\section{Results and Discussion}

\subsection{Sound Absorption Properties of Individual Homogenous Fibers}

3.1.1. Effect of Increasing Fiber Thickness on Sound Absorption Properties of Fibers. Figure 6 shows a consistent increase of SAC in the frequency range $100 \mathrm{~Hz}-1000 \mathrm{~Hz}$ across all sample thicknesses of finger millet straw fiber (F), namely, $10 \mathrm{~mm}$, $20 \mathrm{~mm}$, and $50 \mathrm{~mm}$. SAC decreases in the frequency range $1000 \mathrm{~Hz}-2500 \mathrm{~Hz}$; however, it resumes its upward trend in the frequency range $2500 \mathrm{~Hz}-3500 \mathrm{~Hz}$. SAC further suffers fall in 


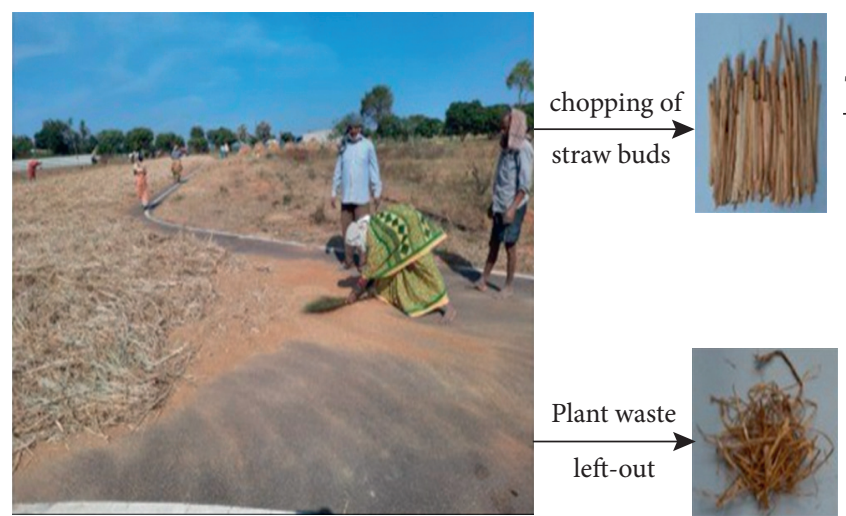

A view of harvesting site where finger millet grains are separated from harvested finger millet plant

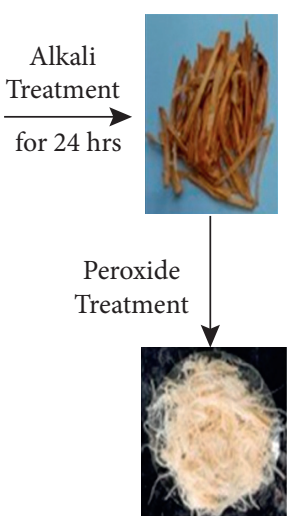

Fibers used for sample preparation

Figure 1: Fiber extraction from finger millet straws at Bandipalya.
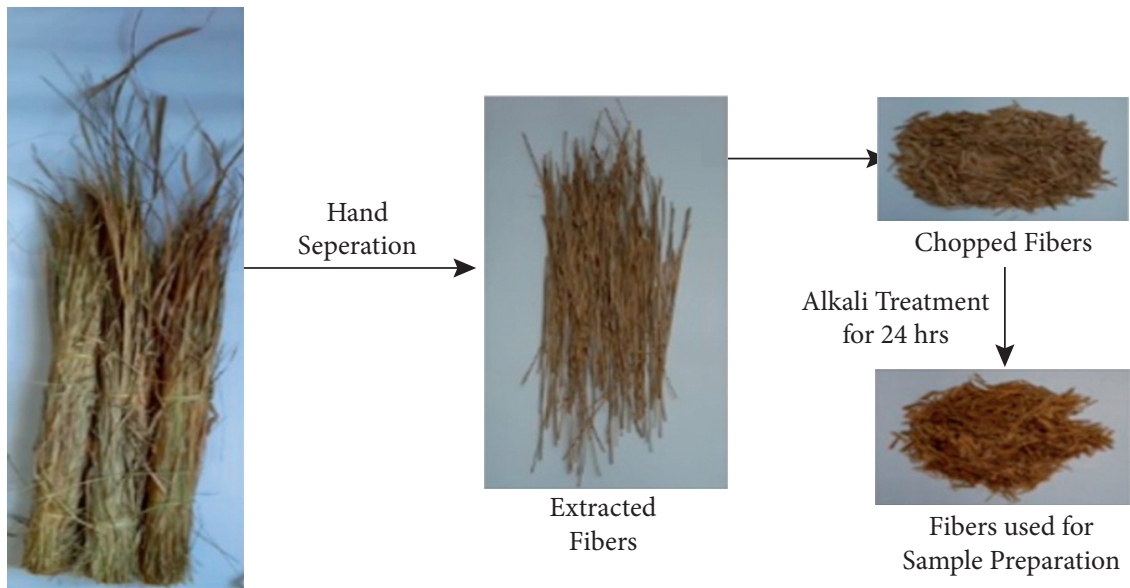

Darbha plant

Figure 2: Darbha fiber extraction from darbha plant.

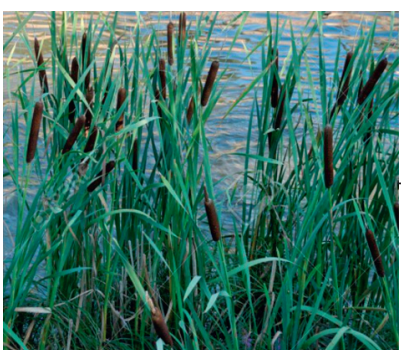

Ripe Bulrush plant

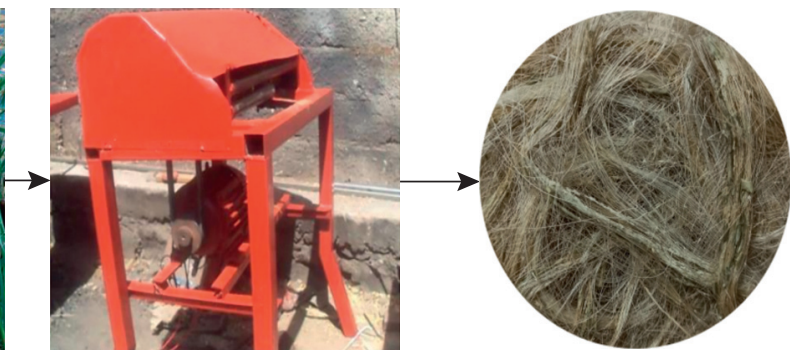

Decorticator

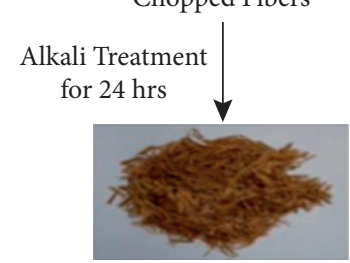

Fibers used for Sample Preparation

FIgURe 3: Fiber extraction from ripe bulrush.

the frequency range $3500 \mathrm{~Hz}-4500 \mathrm{~Hz}$ which may be related to fiber properties of finger millet straw fibers (F). Similarly, SAC is noticed for darbha (D) and ripe bulrush (R) fibers. However, with an exception in SAC value of $\mathrm{D}$ and $\mathrm{R}$ in the frequency range $3500 \mathrm{~Hz}-4500 \mathrm{~Hz}, \mathrm{SAC}$ is consistently increasing higher values of 0.91 . The possible reason for such an exceptional behavior of $\mathrm{D}$ and $\mathrm{R}$ fibers when compared to $\mathrm{F}$ fibers may be owed to the fact that $\mathrm{F}$ fibers have undergone double chemical treatment, i.e., $10 \% \mathrm{NaOH}$ as common with $\mathrm{D}$ and $\mathrm{R}$, along with peroxide treatment (performed only on F fibers). Thus, it can be summarized that all the fibers of F, D, and R have poor sound absorption properties in the common frequency range $1000 \mathrm{~Hz}-2500 \mathrm{~Hz}$ and hence this frequency range is considered a critical frequency range for analysis in this study.

The noise reduction coefficient (NRC) of F fibers has increased from 0.24 to 0.44 when the thickness was increased from $10 \mathrm{~mm}$ to $20 \mathrm{~mm}$. Similarly, it increases from 0.44 to 0.78 when the thicknesses of the fibers are increased from $20 \mathrm{~mm}$ to $50 \mathrm{~mm}$. 
TABle 1: Physical properties of fibers [14].

\begin{tabular}{lccc}
\hline Fiber properties & Finger millet straw fiber $(\mathrm{F})$ & Darbha fiber $(\mathrm{D})$ & Ripe bulrush fiber $(\mathrm{R})$ \\
\hline Fiber length $(\mathrm{mm})$ & $80 \pm 2.5$ & $80 \pm 4$ & $80 \pm 3$ \\
Fiber diameter $(\mu \mathrm{m})$ & $70 \pm 15$ & $60 \pm 5$ & $64.8 \pm 12$ \\
Density $\left(\mathrm{g} / \mathrm{cm}^{3}\right)$ & $1.33 \pm 0.1$ & $1.07 \pm 0.1$ & $1.23 \pm 0.1$ \\
\hline
\end{tabular}

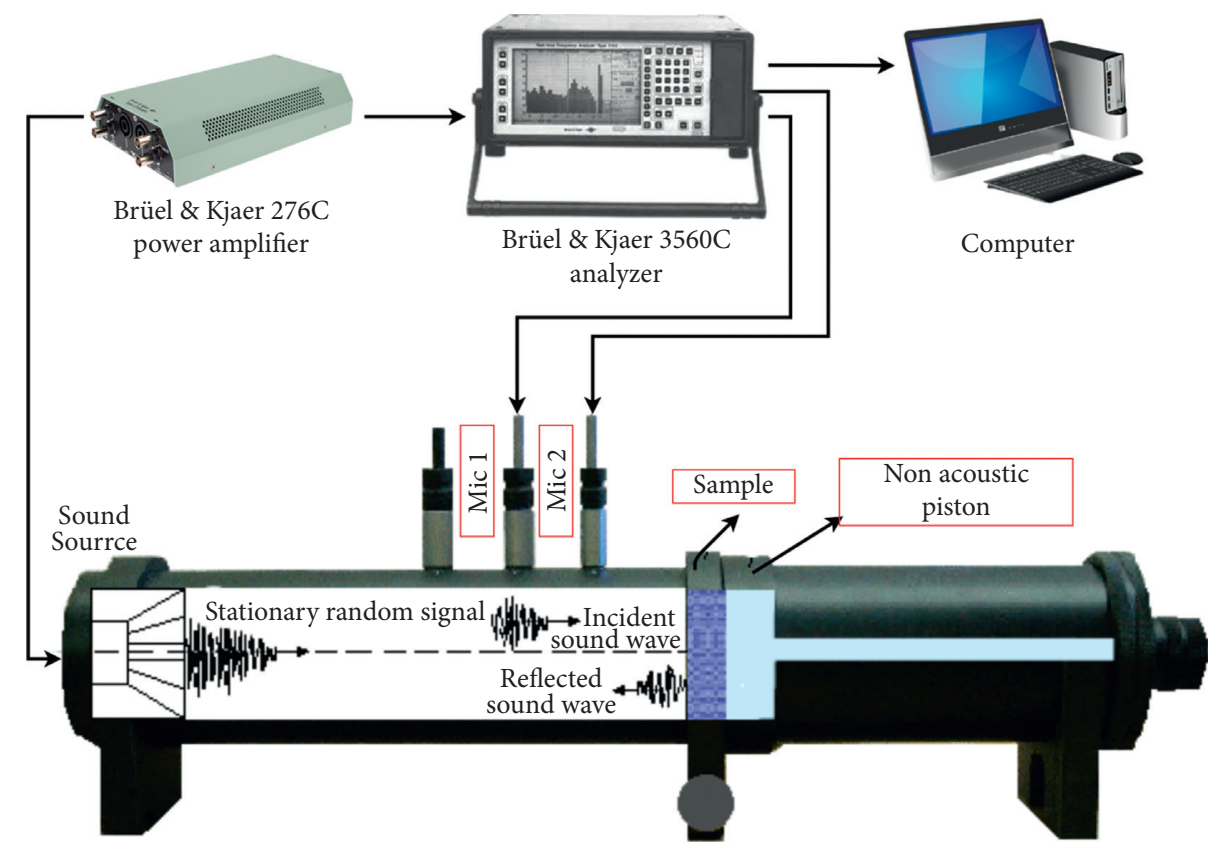

Two microphone impedance test tube with Brüel \& Kjaer 4206 and 4187 microphones

FIGURE 4: Impedance tube setup for testing sound absorption properties.

TABLe 2: Nomenclature of fiber combination.

\begin{tabular}{|c|c|c|}
\hline Sample code & Fibers & Sample thickness \\
\hline S1 & Finger millet straw fiber $(\mathrm{F})$ & $50 \mathrm{~mm}$ \\
\hline S2 & Darbha fiber (D) & $50 \mathrm{~mm}$ \\
\hline S3 & Ripe bulrush fiber $(\mathrm{R})$ & $50 \mathrm{~mm}$ \\
\hline S4 & Finger millet straw fiber/ripe bulrush fiber $(\mathrm{F} / \mathrm{R})$ & $25+25=50 \mathrm{~mm}$ \\
\hline S5 & Ripe bulrush fiber/finger millet straw fiber (R/F) & $25+25=50 \mathrm{~mm}$ \\
\hline S6 & Finger millet straw fiber/darbha fiber $(\mathrm{F} / \mathrm{D})$ & $25+25=50 \mathrm{~mm}$ \\
\hline S7 & Darbha fiber/finger millet straw fiber (D/F) & $25+25=50 \mathrm{~mm}$ \\
\hline S8 & Darbha fiber/ripe bulrush fiber (D/R) & $25+25=50 \mathrm{~mm}$ \\
\hline S9 & Ripe bulrush fiber/darbha fiber (R/D) & $25+25=50 \mathrm{~mm}$ \\
\hline S10 & Finger millet straw fiber + darbha fiber $(F+D$ or $D+F)$ & $50 \mathrm{~mm}$ \\
\hline S11 & Finger millet straw fiber + ripe bulrush fiber $(F+R$ or $R+F))$ & $50 \mathrm{~mm}$ \\
\hline S12 & Darbha fiber + ripe bulrush fiber $(\mathrm{D}+\mathrm{R}$ or $\mathrm{R}+\mathrm{D})$ & $50 \mathrm{~mm}$ \\
\hline
\end{tabular}

Note. / represents the position of the fiber; + represents mixed up fibers.

Sound Source

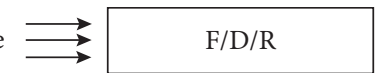

(a)

Sound Source

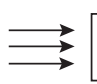

(c)
Sound Source

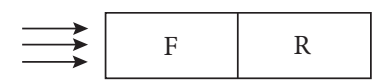

(b)

Sound Source

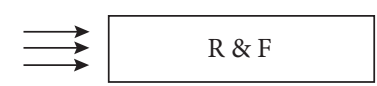

(d)

FIgURE 5: Fiber placement concerning the sound source. (a) Individual fibers: F or D or R. (b) F facing sound source and R behind F. (c) R facing sound source and F behind R. (d) R and F forming homogenous hybrid fiber combinations. 


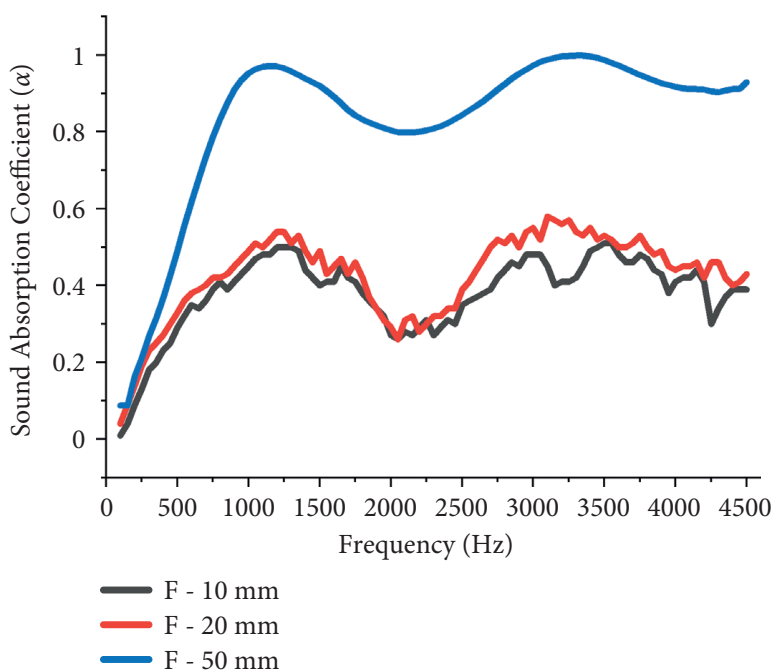

(a)

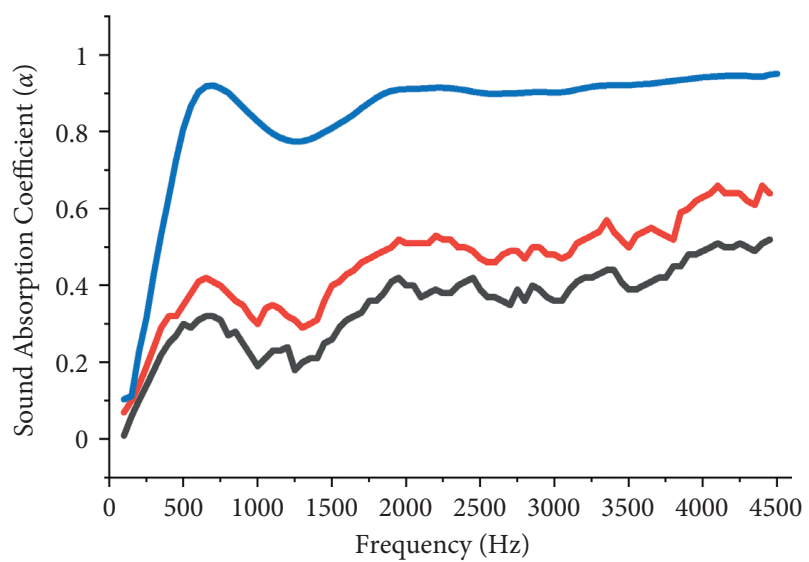

D - $10 \mathrm{~mm}$

D $-20 \mathrm{~mm}$

(b)

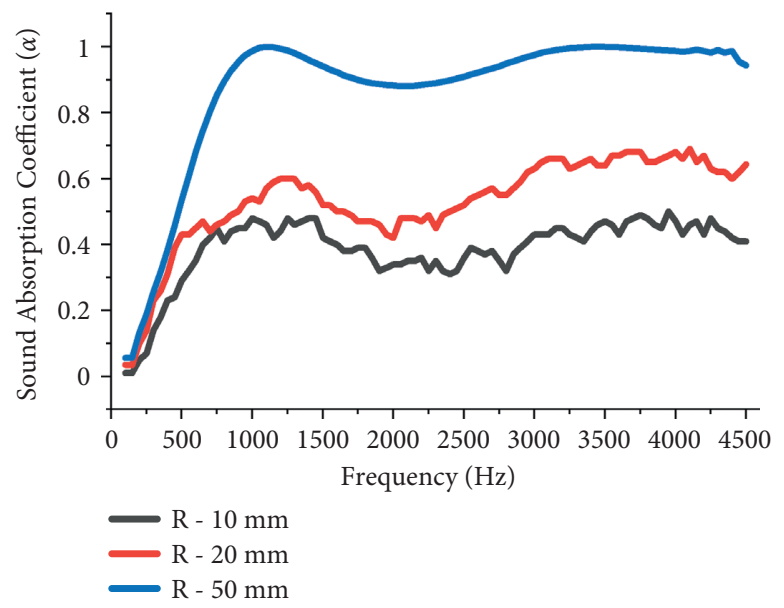

(c)

FiguRE 6: Sound absorption properties of individual fibers for a sample thickness of $10 \mathrm{~mm}, 20 \mathrm{~mm}$, and $50 \mathrm{~mm}$. (a) Finger millet straw fiber. (b) Darbha fiber. (c) Ripe bulrush fibers.

In the same way, the NRC was found for D fibers too. It was observed that NRC has risen from 0.23 to 0.38 for $10 \mathrm{~mm}$ to $20 \mathrm{~mm}$. Again it gets peaked at 0.86 for D fibers when the thickness was increased to $50 \mathrm{~mm}$. For $\mathrm{R}$ fibers, when fiber thickness is increased from $10 \mathrm{~mm}$ to $20 \mathrm{~mm}$, the NRC was found to be 0.24 to 0.36 , respectively. Hence, for $50 \mathrm{~mm}$ R fibers, an NRC of 0.84 was achieved. Considering the SAC values in the entire frequency range of $500 \mathrm{~Hz}-4500 \mathrm{~Hz}$, the sound absorption coefficient for the sample with $50 \mathrm{~mm}$ thickness is found to be more than 0.8 when compared with SAC values of around 0.6 for $20 \mathrm{~mm}$ thickness and around 0.4 for $10 \mathrm{~mm}$ thickness for all the three types of individual fibers of F, D, and R. This has proven that the increase of thickness increases NRC values.

3.1.2. Effect of Adding Air Gap on Sound Absorption Properties of Fibers. The NRC for $50 \mathrm{~mm}$ fiber arrangements were found to be more efficient in absorbing sound than the $10 \mathrm{~mm}$ and $20 \mathrm{~mm}$ thicknesses samples. So, in Figure 7, the comparison on SAC of individual fibers without air gap and with an air gap of $10 \mathrm{~mm}$ was only depicted for $50 \mathrm{~mm}$ samples. The test results indicate a slight increase in values for all three individual fibers when a $10 \mathrm{~mm}$ air gap is provided between the fiber sample and the nonacoustic piston. Also, the NRC of fibers increased to 0.80 (for F fibers), 0.89 (for D fibers), and 0.87 (for $\mathrm{R}$ fibers). These results proved that the SAC value increased when an air gap was provided between the test sample and the sample holder. The same is true in the case for F, D, and R fibers also.

\subsection{Sound Absorption Properties of Hybrid Combinations of Fibers}

3.2.1. Sound Absorption Properties of Stacked Hybrid Combinations. This study aims to explain the effect of fiber type (F, D, and R fibers), thickness (50 $\mathrm{mm})$, and stacking order on SAC values. As illustrated in Figure $8(\mathrm{a})$, the hybrid combination S4 (F/R) exhibits superior values of $0.87 \mathrm{SAC}$ in the frequency range of $1000 \mathrm{~Hz}-2500 \mathrm{~Hz}$ when compared to the individual fiber samples S1 and S3. However, S5 (R/F) exhibits similar 


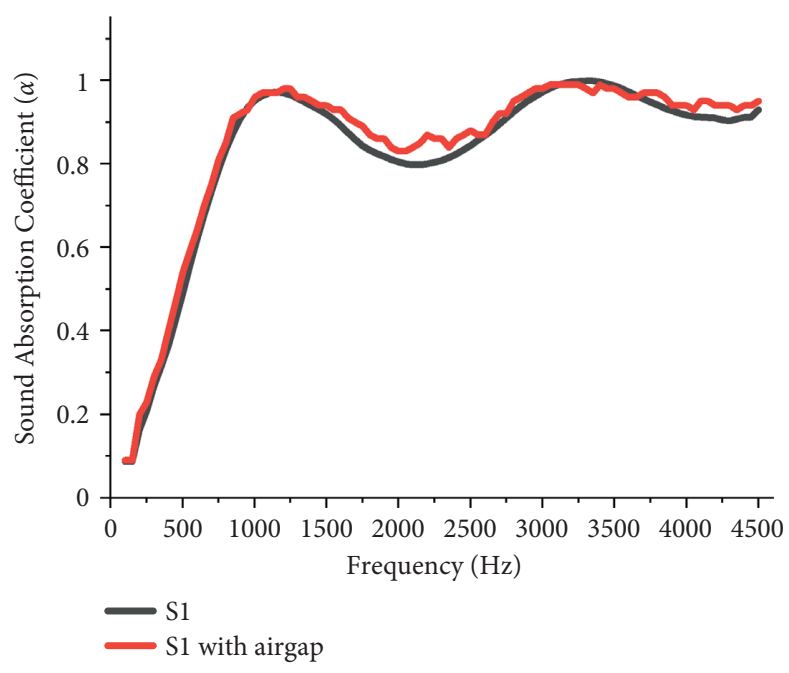

(a)

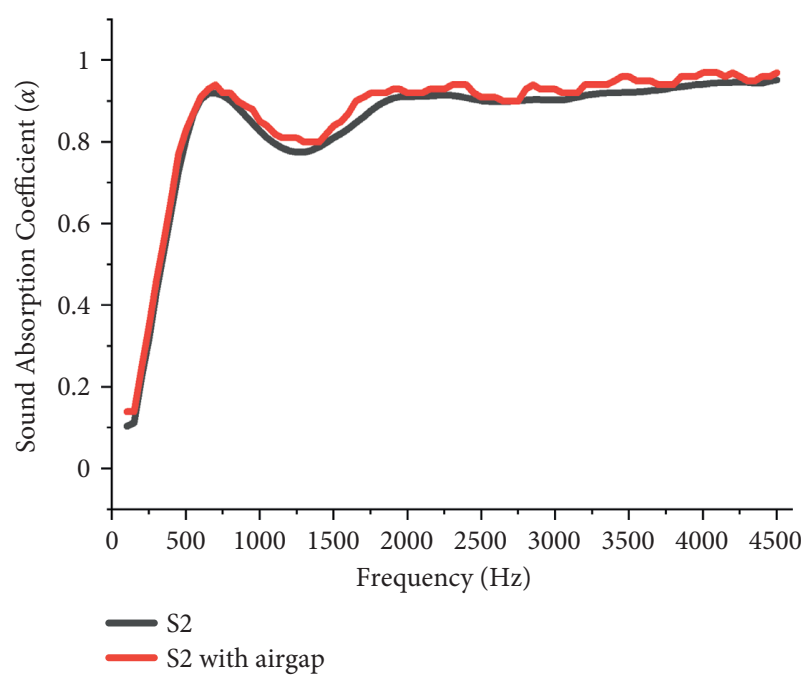

(b)

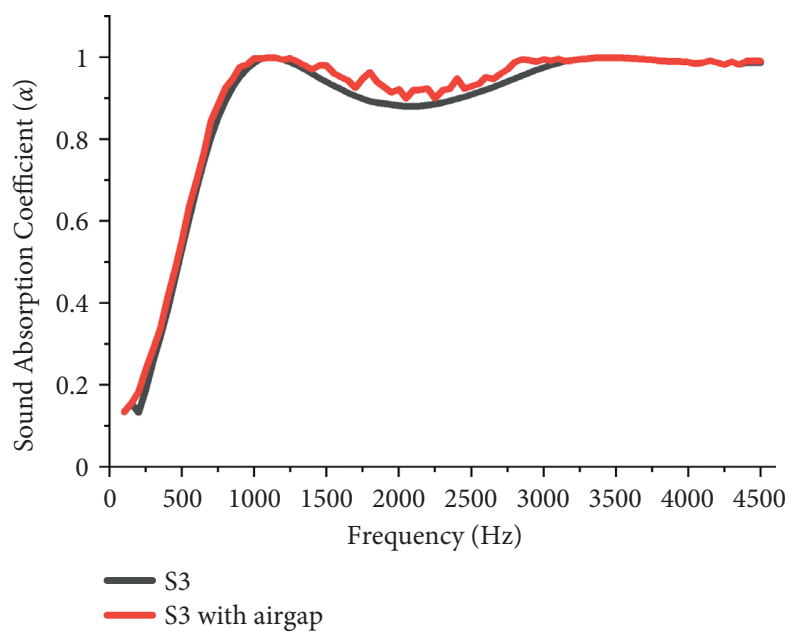

(c)

FIGURE 7: Sound absorption properties of individual fibers with and without air gap of $10 \mathrm{~mm}$. (a) Finger millet straw fiber. (b) Darbha fiber. (c) Ripe bulrush fibers.

values to $\mathrm{S} 1$ and $\mathrm{S} 3$ in the frequency range of $1000 \mathrm{~Hz}-2500 \mathrm{~Hz}$. In this combination, it is understood that if the finger millet faces the sound source, the SAC will tend to increase. Similarly, in S6 and S7 combination, S6 exhibited excellent absorption compared to S7 of 0.89 $\mathrm{SAC}$ in the frequency range $1000 \mathrm{~Hz}-2500 \mathrm{~Hz}$ as illustrated in Figure 8(b). The primary reason for this behavior of hybrid samples is that the absorption properties of the samples are dependent on the fiber type and stacked arrangement of the fibers exposed to the sound source. In the frequency range of $1000 \mathrm{~Hz}-2500 \mathrm{~Hz}, \mathrm{~S} 8$ and S9 exhibit similar acoustic properties of S2 and S3 samples, respectively, as illustrated in Figure 8(c). According to Figures 8(d) and 8(f), S9 (R/D) and S8 (D/ R) have achieved higher sound absorption value than S5 $(\mathrm{R} / \mathrm{F})$ and $\mathrm{S} 7 \mathrm{D} / \mathrm{F})$, respectively, for the frequency range $1000 \mathrm{~Hz}-2500 \mathrm{~Hz}$. While both $\mathrm{S} 9(\mathrm{R} / \mathrm{D})$ and $\mathrm{S} 5(\mathrm{R} / \mathrm{F})$ exhibit similar absorption characteristics when $\mathrm{R}$ fibers are exposed to a sound source, they achieve greater absorption when $\mathrm{D}$ or $\mathrm{F}$ are exposed to a sound source. The reason for this difference in absorption behavior between S9 and S5 can be attributed to the fiber type (F or D) that supports the R fibers. However, there is only a slight difference in the sound absorption behavior of S7 $(\mathrm{D} / \mathrm{F})$ and $\mathrm{S} 8(\mathrm{D} / \mathrm{R})$ and no significant difference in the sound absorption behavior of $\mathrm{S} 4(\mathrm{~F} / \mathrm{R})$ and $\mathrm{S} 6(\mathrm{~F} / \mathrm{D})$ for the aforementioned critical frequencies. From the SACs acquired for the different samples (S4 to S9), the NRC was calculated as 0.86 (S4 sample), 0.865 (S5 sample), 0.89 (S6 sample), 0.88 (S7 sample), 0.88 (S8 sample), and 0.90 (S9 sample), respectively.

\subsubsection{Sound Absorption Properties of Homogenous Hybrid} Fiber Combinations. As illustrated in Figures 9(a) and 9(c), the sound absorption performance of homogenous hybrid combinations (S10 and S12) are superior to that of individual fibers (S2) over the frequency range of $1000 \mathrm{~Hz}$ to $2500 \mathrm{~Hz}$. The test results indicate that darbha fibers (D) have low sound 

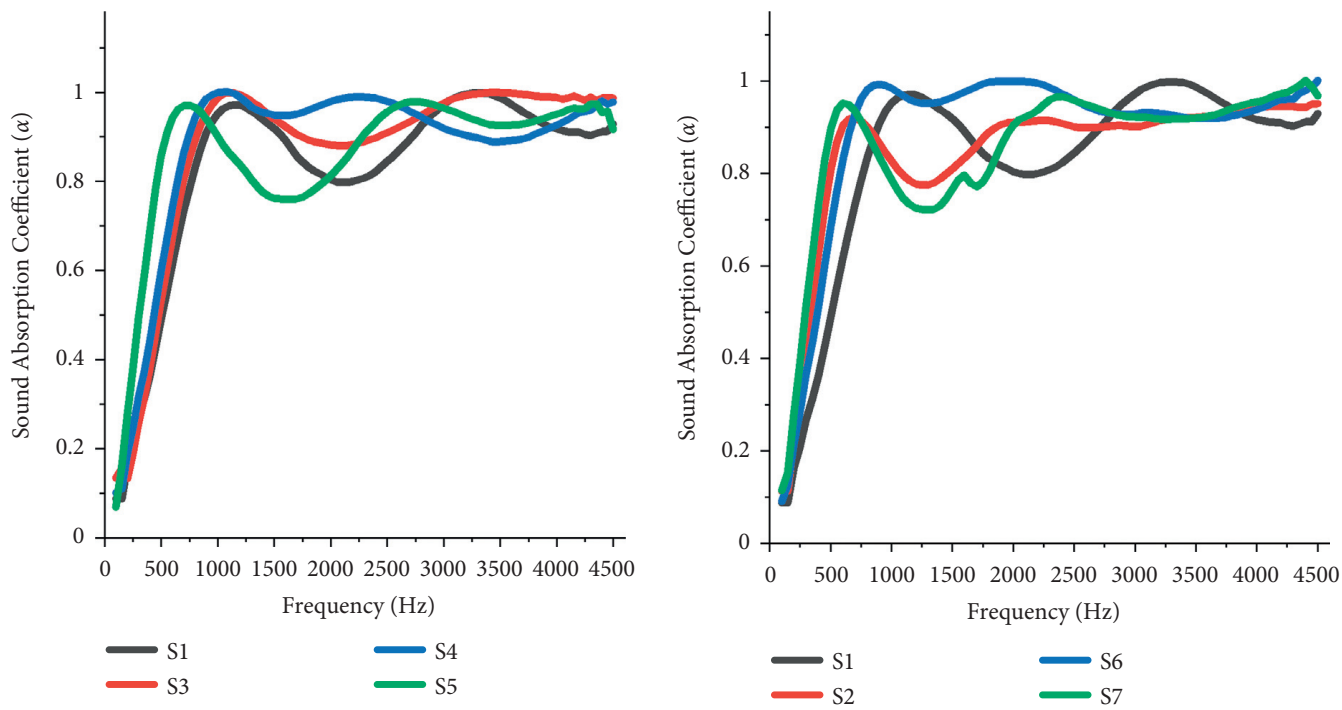

(a)

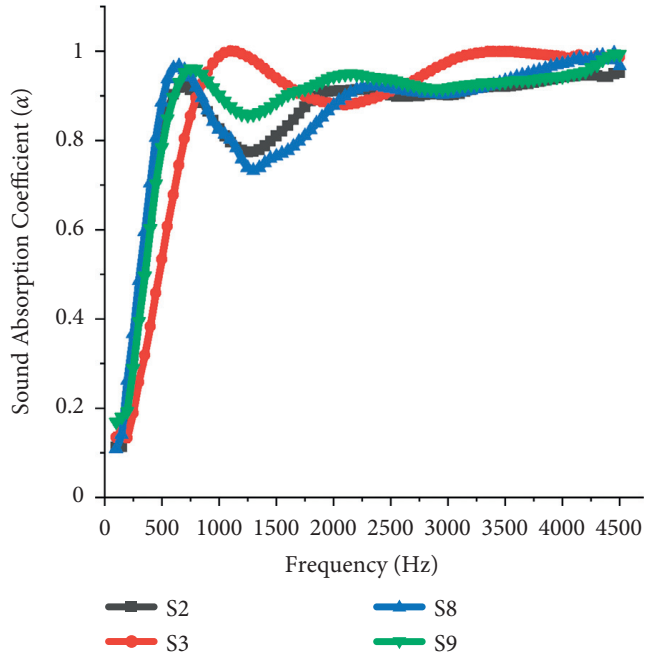

(b)

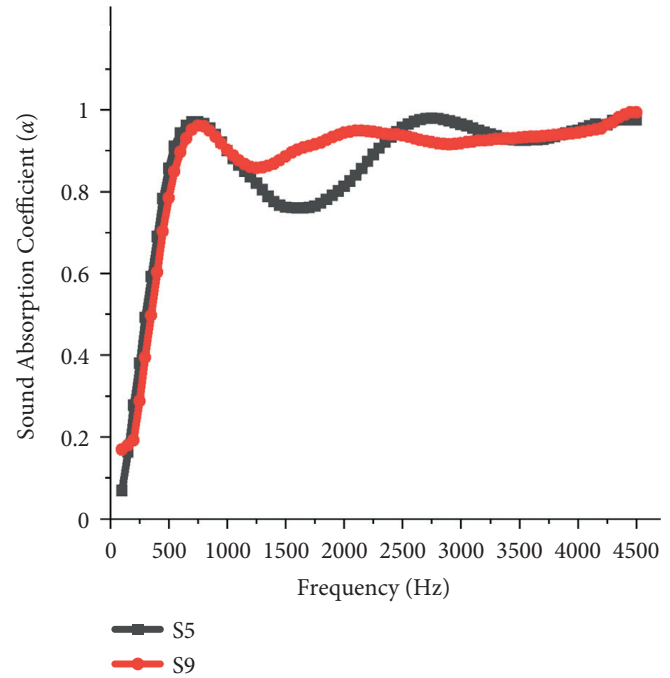

(c)

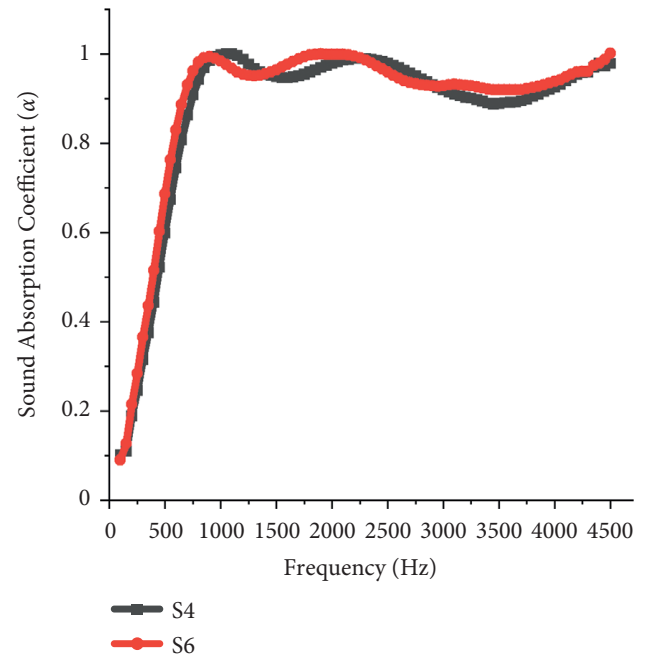

(d)

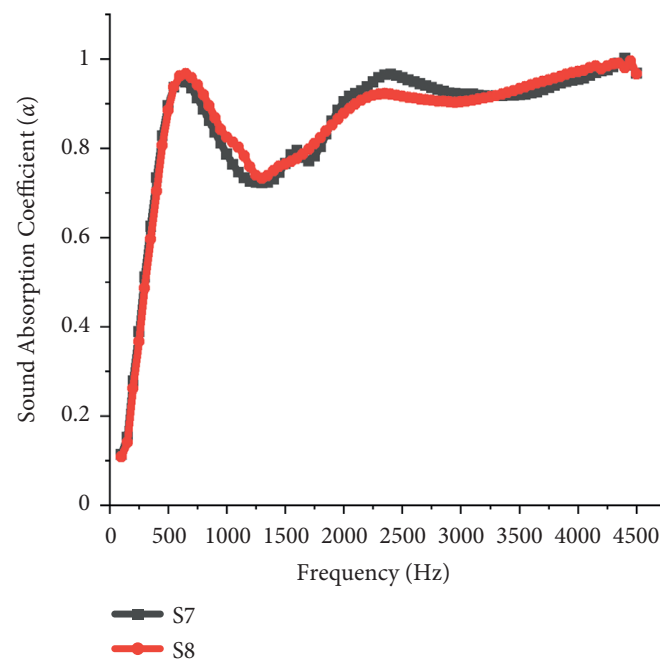

(e)

(f)

Figure 8: Comparison of sound absorption properties of various stacked hybrid combinations. (a) S4 and S5 with S1 and S3, (b) S6 and S7 with S1 and S2, (c) S8 and S9 with S2 and S3, (d) S5 with S9, (e) S4 with S6, and (f) S7 with S8. 

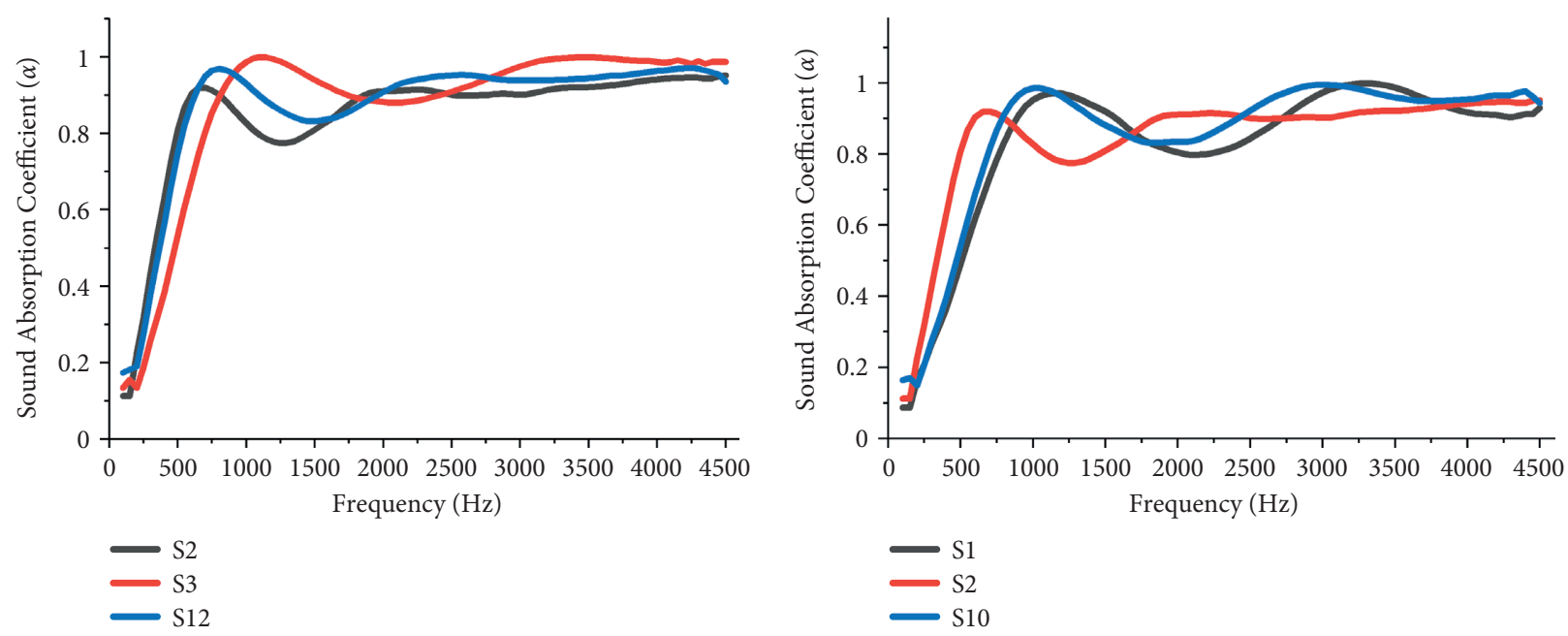

(a)
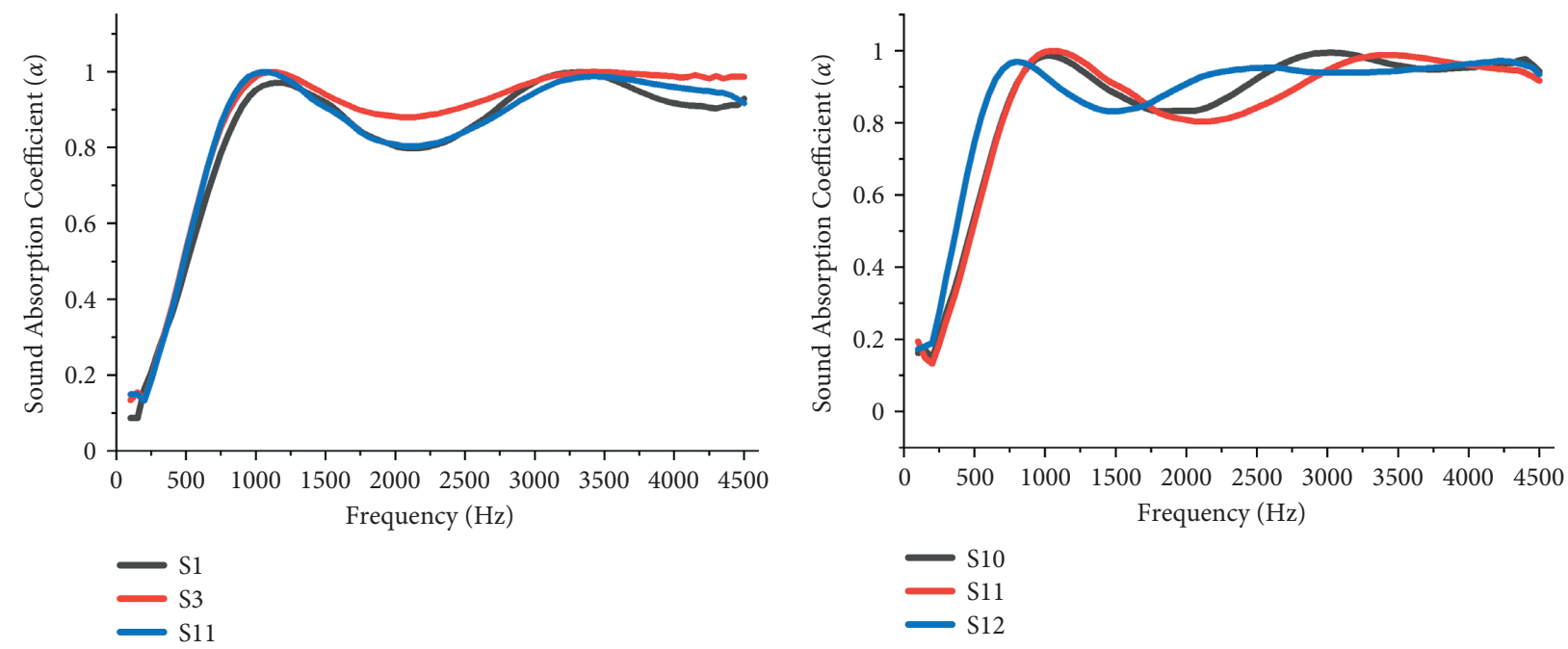

(c)

(d)

FIGURE 9: Comparison of sound absorption properties of homogenous hybrid fiber combinations with individual fibers: (a) S10 with S1 and S2, (b) S11 with S1 and S3, (c) S12 with S2 and S3, and (d) S10, S11, and S12 combinations (S1, S2, and S3). Furthermore, the sound absorption properties of homogenous hybrid combinations are comparable to those of stacked hybrid combinations.

absorption of 0.78 for individual fiber arrangement but exhibited superior acoustic properties when combined with $\mathrm{F}$ and $\mathrm{R}$ fibers. This proves that hybridization will tend to increase the SAC and NRC of the fibers. It can be concluded from Figures 9(a) and 9(b) that there is no significant difference in the sound absorption properties of finger millet straw fibers ( $F$ fibers) when used alone but in combination with $\mathrm{D}$ and $\mathrm{R}$ fibers it exhibited better SAC and NRC for the frequency range $1000 \mathrm{~Hz}-2500 \mathrm{~Hz}$. This is experimentally studied also for the ripe bulrush fibers $(\mathrm{R})$, whose results revealed that it exhibited superior sound absorption with $\mathrm{F}$ and $\mathrm{D}$ fibers than individual fiber arrangements as illustrated in Figures 9(b) and 9(c) for the critical frequency range of $1000 \mathrm{~Hz}-2500 \mathrm{~Hz}$. However, the homogenous hybrid combination exhibits acceptable NRC values of $0.90,0.91$, and 0.93 for S10, S11, and S12. Hybrid Fiber Combinations with Their Homogenous Hybrid
Fiber Combinations. NRC was found to be more for the homogenous combinations (S10, S11, and S12) in the critical frequency range than their individual fibers ( $S 1$, S2 and S3). As illustrated in Figure 10(a), S11 has superior absorption properties when compared to S4 and S5. Similarly, S10 and S12 have better sound absorption characteristics when compared with other combinations (S6-S7 and S8-S9), respectively. This happens due to the better interlocking of the fibers and the sound source finds it a critical path to travel along. Finally, the sound gets arrested or absorbed. The NRC for all the combinations is listed in Table 2 for better clarity. Table 3 lists the statistical data that represent the increase of NRC in percentage for all the combinations in Table 4.

The noise reduction coefficient (NRC) of previously published articles were compared with the present work for a better understanding of the increase in sound absorption properties as shown in Figure 11. 


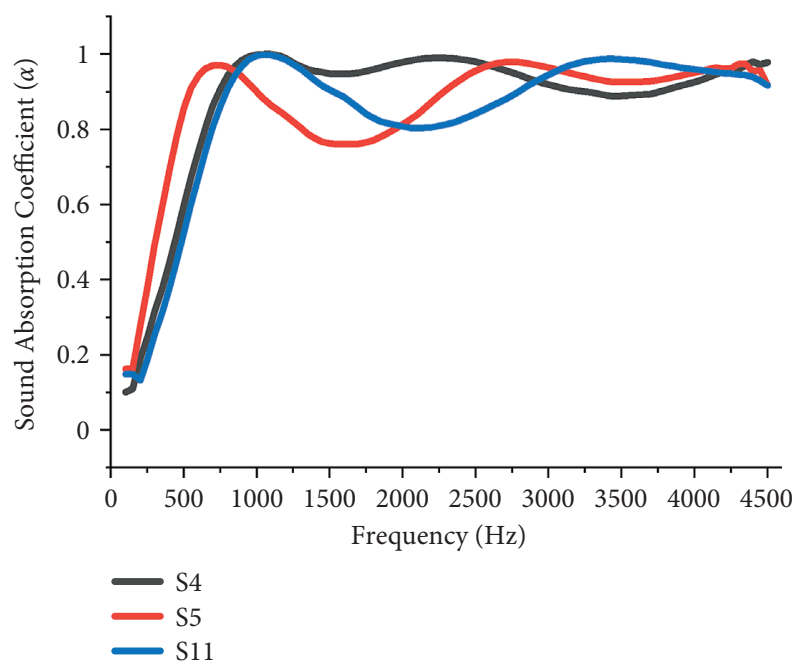

(a)

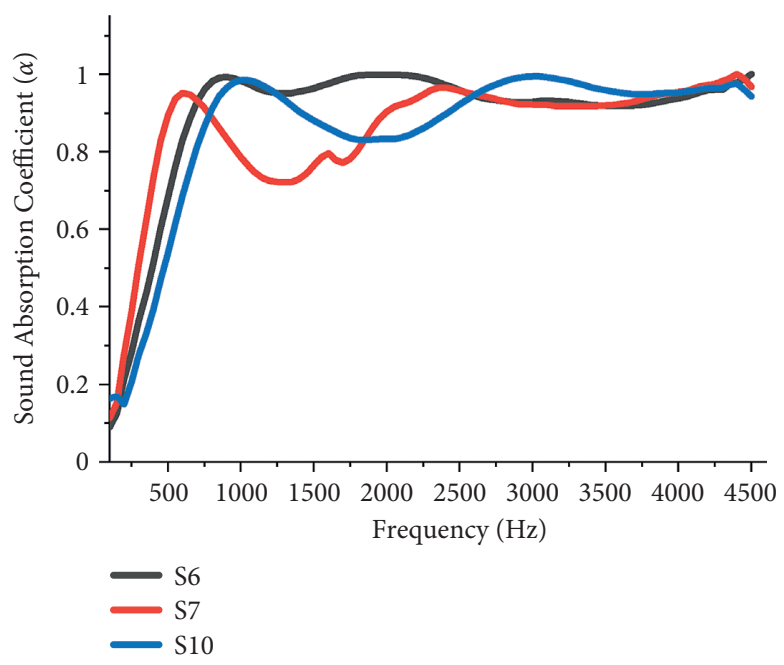

(b)

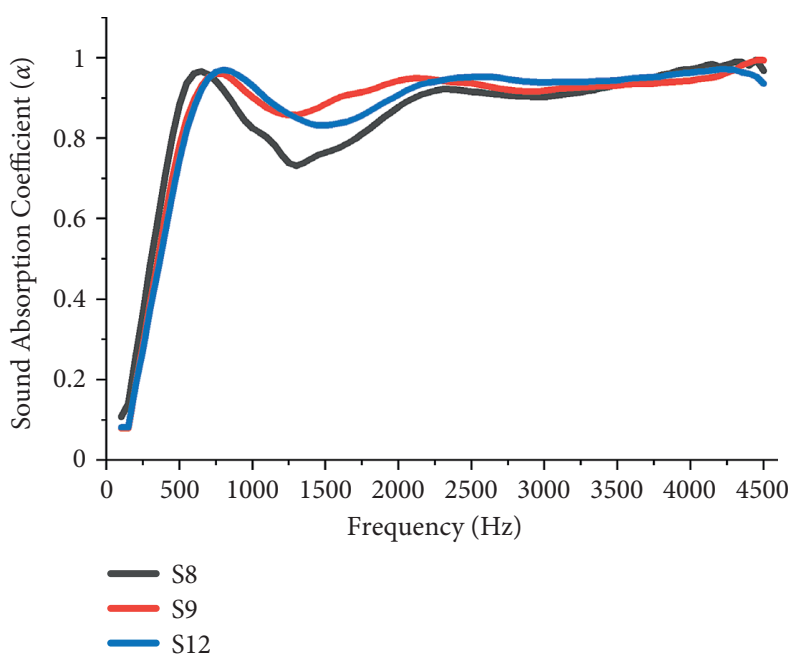

(c)

Figure 10: Comparison of sound absorption properties of stacked hybrid combinations of fibers with their homogenous hybrid combinations: (a) S4 and S5 with S11, (b) S6 and S7 with S10, and (c) S8 and S9 with S12.

TABLE 3: NRC for different fiber combinations.

\begin{tabular}{lcc}
\hline Sample code & Fibers & Sample thickness \\
\hline S1 & Finger millet straw fiber (F) & $50 \mathrm{~mm}$ \\
S2 & Darbha fiber (D) & $50 \mathrm{~mm}$ \\
S3 & Ripe bulrush fiber (R) & $50 \mathrm{~mm}$ \\
S4 & Finger millet straw fiber/ripe bulrush fiber (F/R) & 0.78 \\
S5 & Ripe bulrush fiber/finger millet straw fiber (R/F) & 0.84 \\
S6 & Finger millet straw fiber/darbha fiber (F/D) & 0.86 \\
S7 & Darbha fiber/finger millet straw fiber (D/F) & $25+25=50 \mathrm{~mm}$ \\
S8 & Darbha fiber/ripe bulrush fiber (D/R) & $25+25=50 \mathrm{~mm}$ \\
S9 & Ripe bulrush fiber/darbha fiber (R/D) & $25+25=50 \mathrm{~mm}$ \\
S10 & Finger millet straw fiber + darbha fiber (F + D or D + F) & $25+25=50 \mathrm{~mm}$ \\
S11 & Finger millet straw fiber + ripe bulrush fiber (F+R or R+F) & $25+25=50 \mathrm{~mm}$ \\
S12 & Darbha fiber + ripe bulrush fiber (D + R or R + D) & $25+25=50 \mathrm{~mm}$ \\
& & $50 \mathrm{~mm}$
\end{tabular}


TABLE 4: Statistical data analysis: NRC increase percentage with comparison to all combinations.

\begin{tabular}{|c|c|c|c|c|c|c|c|c|c|c|c|c|c|}
\hline \multirow{2}{*}{ Sample code } & \multirow{2}{*}{ NRC } & \multicolumn{12}{|c|}{ Increases in NRC values (\%) } \\
\hline & & S1 & S2 & S3 & S4 & S5 & S6 & S7 & S8 & S9 & S10 & S11 & S12 \\
\hline S1 & 0.78 & 0 & 9.30 & 7.14 & 9.30 & 9.83 & 12.36 & 11.36 & 11.36 & 13.33 & 13.33 & 14.29 & 16.13 \\
\hline S2 & 0.86 & 10.26 & 0 & 2.38 & 0.00 & 0.58 & 3.37 & 2.27 & 2.27 & 4.44 & 4.44 & 5.49 & 7.53 \\
\hline S3 & 0.84 & 7.69 & 2.33 & 0 & 2.33 & 2.89 & 5.62 & 4.55 & 4.55 & 6.67 & 6.67 & 7.69 & 9.68 \\
\hline S4 & 0.86 & 10.26 & 0 & 2.38 & 0 & 0.58 & 3.37 & 2.27 & 2.27 & 4.44 & 4.44 & 5.49 & 7.53 \\
\hline S5 & 0.865 & 10.90 & 0.58 & 2.98 & 0.58 & 0 & 2.81 & 1.70 & 1.70 & 3.89 & 3.89 & 4.95 & 6.99 \\
\hline S6 & 0.89 & 14.10 & 3.49 & 5.95 & 3.49 & 2.89 & 0 & 1.14 & 1.14 & 1.11 & 1.11 & 2.20 & 4.30 \\
\hline S7 & 0.88 & 12.82 & 2.33 & 4.76 & 2.33 & 1.73 & 1.12 & 0 & 0 & 2.22 & 2.22 & 3.30 & 5.38 \\
\hline S8 & 0.88 & 12.82 & 2.33 & 4.76 & 2.33 & 1.73 & 1.12 & 0 & 0 & 2.22 & 2.22 & 3.30 & 5.38 \\
\hline S9 & 0.90 & 15.38 & 4.65 & 7.14 & 4.65 & 4.05 & 1.12 & 2.27 & 2.27 & 0 & 0 & 1.10 & 3.23 \\
\hline S10 & 0.90 & 15.38 & 4.65 & 7.14 & 4.65 & 4.05 & 1.12 & 2.27 & 2.27 & 0 & 0 & 1.10 & 3.23 \\
\hline S11 & 0.91 & 16.67 & 5.81 & 8.33 & 5.81 & 5.20 & 2.25 & 3.41 & 3.41 & 1.11 & 1.11 & 0 & 2.15 \\
\hline S12 & 0.93 & 19.23 & 8.14 & 10.71 & 8.14 & 7.51 & 4.49 & 5.68 & 5.68 & 3.33 & 3.33 & 2.20 & 0 \\
\hline
\end{tabular}

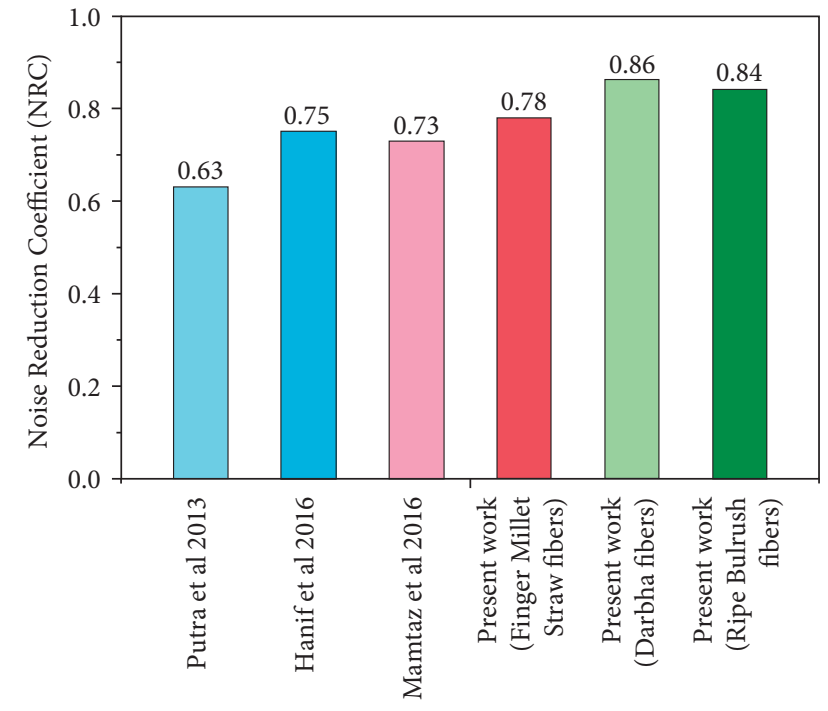

FIGURE 11: Comparison of sound absorption properties of present work with previously published work $[6,26,34]$.

\section{Conclusion}

The sound absorption properties of three plant-based natural fibers, finger millet straw fiber (F), darbha fiber (D), and ripe bulrush fibers $(\mathrm{R})$, are investigated in this research study. At first, fibers are studied individually, secondly in stack-up hybrid combination, and finally in homogenous hybrid combinations. The SAC values of individual fibers F, $\mathrm{D}$, and $\mathrm{R}$ increased significantly with an increase in sample thickness from $10 \mathrm{~mm}$ to $20 \mathrm{~mm}$ and then for $50 \mathrm{~mm}$ and also increased with the addition of an air gap of $10 \mathrm{~mm}$ between fiber sample and sample holder. Additionally, test results indicate that the fiber type and stack-up arrangement of the fibers play a significant role in determining the sound absorption properties (SAC and NRC). Darbha fibers (D) exhibited superior sound absorption of $0.86 \mathrm{NRC}$ as an individual fiber arrangement. Also, darbha fibers when added with ripe bulrush fibers either in stacked up and homogenous hybrid combinations exhibited superior sound absorption compared to the other combinations in the critical frequency range of $500 \mathrm{~Hz}-2000 \mathrm{~Hz}$. From these studies, it was concluded that the darbha fiber will help to enhance the sound absorption properties either individually or in hybrid combinations.

\section{Data Availability}

The data used to support the findings of this study are included in the article.

\section{Conflicts of Interest}

The authors declare that there are no conflicts of interest regarding the publication of this article.

\section{Acknowledgments}

This project was funded by the Researchers Supporting Project under number RSP2021/405, King Saud University, Riyadh, Saudi Arabia.

\section{References}

[1] A. Kumar and S. Kumar, "Development of paving blocks from synergistic use of red mud and fly ash using geopolymerization," Construction and Building Materials, vol. 38, pp. 865-871, 2013.

[2] L. Prabhu, V. Krishnaraj, S. Sathish, S. GokulKumar, and N. Karthi, "Study of mechanical and morphological properties of jute-tea leaf fiber reinforced hybrid composites: effect of glass fiber hybridization," Materials Today Proceedings, vol. 27, pp. 2372-2375, 2020.

[3] L. Prabhu, V. Krishnaraj, S. Gokulkumar, S. Sathish, M. R. Sanjay, and S. Siengchin, "Mechanical, chemical and sound absorption properties of glass/kenaf/waste tea leaf fiber-reinforced hybrid epoxy composites," Journal of Industrial Textiles, p. 152808372095739, 2020.

[4] E. Taban, A. Tajpoor, M. Faridan, S. E. Samaei, and M. H. Beheshti, "Acoustic absorption characterization and prediction of natural coir fibers," Acoustics Australia, vol. 47, no. 1, pp. 67-77, 2019.

[5] K. H. Or, A. Putra, and M. Zulkefli Selamat, "Oil palm empty fruit bunch fibers as sustainable acoustic absorber," Applied Acoustics, vol. 119, pp. 9-16, 2017.

[6] K. H. Or, A. Putra, M. Zulkefli Selamat, M. J. M. Nor, M. H. Hassan, and I. Prasetiyo, "Sound absorption of 
extracted pineapple-leaf fibers," Applied Acoustics, vol. 136, pp. 9-15, 2018.

[7] S. Gokulkumar, P. Thyla, L. Prabhu, and S. Sathish, "Characterization and comparative analysis on mechanical and acoustical properties of Camellia sac/glass fiber hybrid polymer composites," Journal of Natural Fibers, vol. 18, no. 7, pp. 978-994, 2021.

[8] S. Gokulkumar, P. R. Thyla, L. Prabhu, S. Sathish, and N. Karthi, "A comparative study on epoxy based composites filled with pineapple/areca/ramie hybridized with industrial tea leaf wastes/GFRP," Materials Today Proceedings, vol. 27, pp. 2474-2476, 2020.

[9] H. Ayou, H. Zhao, and J. Y. Chen, "Kenaf/polypropylene nonwoven composites: the in- fluence of manufacturing conditions on mechanical, thermal, and acoustical performance," Composites Part B: Engineering, vol. 54, pp. 44-51, 2013.

[10] N. H. Bhingare and S. Prakash, "Enhancement in fire retardant Properties of Coconut Coir/Polyurethane acoustic composites," Journal of Natural Fibers, pp. 1-6, 2020.

[11] E. Jayamani, S. Hamdan, S. Kok Heng, Md R. Rahman, and M. K. B. Bakri, "Acoustical, thermal, and morphological properties of zein reinforced oil palm empty fruit bunch fiber bio-composites," Journal of Applied Polymer Science, vol. 133, no. 43, 2016.

[12] S. Gokulkumar, P. R. Thyla, R. ArunRamnath, and N. Karthi, "Acoustical analysis and drilling process optimization of Camellia Sinensis/Ananas Comosus/GFRP/epoxy composites by TOPSIS for indoor applications," Journal of Natural Fibers, vol. 18, no. 12, pp. 2284-2301, 2021.

[13] H. R. Taghiyari, H. Militz, P. Antov, and A. N. Papadopoulos, "Effects of wollastonite on fire properties of particleboard made from wood and chicken feather fibers," Coatings, vol. 11, no. 5 , p. $518,2021$.

[14] V. K. Singh and S. Mukhopadhyay, "Studies on the effect of hybridization on sound insulation of coir-banana-polypropylene hybrid b," Journal of Natural Fibers, pp. 1-10, 2020.

[15] A. Putra, T. Oliveira, M. Souli, and D. H. Kassim, "Characterizing and modeling of acoustical performance of natural sound absorber," in Multiphysics Simulations in Automotive and Aerospace Applications, pp. 49-64, 2021.

[16] T. Hassan, H. Jamshaid, R. Mishra et al., "Factors affecting acoustic properties of natural-fiber-based materials and composites: a review," Textiles, vol. 1, no. 1, pp. 55-85, 2021.

[17] M. A. A. Aziz and K. A. M. Sari, "Comparison of sound absorption coefficient for natural fiber," Progress in Engineering Application and Technology, vol. 2, no. 1, pp. 157-163, 2021.

[18] E. M. Tudor, A. Dettendorfer, G. Kain, M. C. Barbu, R. Réh, and Ľ. Krišták, "Sound-absorption coefficient of bark-based insulation panels," Polymers, vol. 12, no. 5, p. 1012, 2020.

[19] E. M. Tudor, L. Kristak, M. C. Barbu et al., "Acoustic properties of larch bark panels," Forests, vol. 12, no. 7, p. 887, 2021.

[20] H. Olcay and E. D. Kocak, "Rice plant waste reinforced polyurethane composites for use as the acoustic absorption material," Applied Acoustics, vol. 173, p. 107733, 2021.

[21] Azhar, A. Imran, and K. A. M. Sari, "Comparison of sound absorption coefficient on natural fiber and recycle materials panel," Progress in Engineering Application and Technology, vol. 2, no. 1, pp. 225-233, 2021.

[22] S. Prabhakaran, V. Krishnaraj, M. S. kumar, and R. Zitoune, "Sound and vibration damping properties of flax fiber reinforced composites," Procedia Engineering, vol. 97, pp. 573-581, 2014.

[23] J. E. Femandez, "Flax fiber reinforced concrete-a natural fiber biocomposite for sustainable building materials," WIT Transactions on The Built Environment, vol. 59, 2002.

[24] C. Buksnowitz, R. Adusumalli, A. Pahler, H. Sixta, and W. Gindl, "Acoustical properties of Lyocell, hemp, and flax composites," Journal of Reinforced Plastics and Composites, vol. 29, no. 20, pp. 3149-3154, 2010.

[25] S. Ehsan Samaei, U. Berardi, E. Taban, P. Soltani, and S. Mohammad Mousavi, "Natural fibro-granular composite as a novel sustainable sound-absorbing material," Applied Acoustics, vol. 181, p. 108157, 2021.

[26] H. Mamtaz, M. Hosseini Fouladi, M. Z. Nuawi, S. Narayana Namasivayam, M. Ghassem, and M. Al-Atabi, "Acoustic absorption of fibro-granular composite with cylindrical grains," Applied Acoustics, vol. 126, pp. 58-67, 2017.

[27] U. Berardi and G. Iannace, "Acoustic characterization of natural fibers for sound absorption applications," Building and Environment, vol. 94, pp. 840-852, 2015.

[28] Z. Y. Lim, A. Putra, M. J. M. Nor, and M. Y. Yaakob, "Sound absorption performance of natural kenaf fibres," Applied Acoustics, vol. 130, pp. 107-114, 2018.

[29] E. Taban, P. Soltani, U. Berardi et al., "Measurement, modeling, and optimization of sound absorption performance of Kenaf fibers for building applications," Building and Environment, vol. 180, p. 107087, 2020.

[30] A. Hao, H. Zhao, and J. Y. Chen, "Kenaf/polypropylene nonwoven composites: the influence of manufacturing conditions on mechanical, thermal, and acoustical performance," Composites Part B: Engineering, vol. 54, pp. 44-51, 2013.

[31] T. M. Pham, "Enhanced properties of high-silica rice husk ash-based geopolymer paste by incorporating basalt fibers," Construction and Building Materials, vol. 245, no. 2020, p. 118422.

[32] M. Ramesh, C. Deepa, M. Tamil Selvan, and K. Hemachandra Reddy, "Effect of alkalization on characterization of ripe bulrush (Typha domingensis) grass fiber reinforced epoxy composites," Journal of Natural Fibers, pp. 1-12, 2020.

[33] ISO 10534-2, Acoustics: Determination of Sound Absorption Coefficient and Impedance in Impedances Tubes. Part 2: Transfer-Function Method, ISO, Geneva, Switzerland, 1998.

[34] M. Mhd Haniffa, Y. Ching, L. Abdullah, S. Poh, C. Chuah, and H. Cheng, "Review of bionanocomposite coating films and their applications," Polymers, vol. 8, no. 7, p. 246, 2016. 